\title{
Um estudo exploratório sobre os recursos humanos e a tomada de decisão
}

\author{
Mauro Laruccia
}

\begin{abstract}
Mauro Laruccia é pós doutor em comunicação, doutor comunicação e semiótica pela PUCSP, graduado e especializado em comunicação. Pesquisador e editor de revistas acadêmicas Qualis, é professor de graduação e mestrado. Atua na academia e no mercado de comunicação em São Paulo.
\end{abstract}

\section{Resumo}

Este trabalho tem por objetivo discutir os Recursos Humanos como o personagem principal do processo de tomada de decisão. O problema de pesquisa foi como o RH contribui para a tomada de decisão estratégica? A hipótese de pesquisa é que tomada de decisão se torna completa quando as pessoas estão seguras para defendê-las e torná-las em ações ao tomar decisões importantes para as organizações. Na pesquisa foi utilizado o método survey, aplicando-se um questionário a 191 alunos universitários. O questionário apresentou-se com 13 (vinte e quatro) perguntas. O primeiro bloco contemplou os dados sobre o perfil dos respondentes e posteriormente as perguntas foram referentes ao tema $\mathrm{RH}$ e Tomada de Decisão. Foi elaborado análise de confiabilidade dos dados para testar o constructo e medir a consistência do questionário. Os coeficientes do Alfa de Cronbach não padronizado e padronizado são, respectivamente, 0,868 e 0,871 com base em 5 item (variáveis), valores recomendados pela literatura estatística. A pesquisa revelou que os alunos estão satisfeitos com a credibilidade e confiança $(44,64 \%)$ e com o comprometimento da empresa $(42,59 \%)$. Revelou, também, que estão parcialmente insatisfeitos com o compartilhamento das atividades (35,71\%); com o relacionamento interpessoal e com a comunicação $(39,29 \%)$. Revelou, ainda, que o RH contribui para a tomada de decisão de sua empresa (72\%), bem como que os tomadores de decisão nas empresas avaliam os riscos que acompanham suas decisões $(86 \%)$.

Palavras-chave: Tomada de decisão, Gestão de pessoas, Estratégia.

\section{Abstract}

This paper aims to discuss the Human Resources as the main character of the process of decision-making. The research problem was how HR contributes to the strategic decision-making? The research hypothesis is that decision-making becomes complete when people are safe to defend them and make them into actions to make important decisions for organizations. In the research method was survey by applying a questionnaire to 191 college students, by questionnaire with 13 (twenty four) questions. The first block included the data on the profile of respondents and then the questions were related to the topic of HR and Decision Making. Was prepared reliability analysis of the data to test the construct and measure the consistency of the questionnaire. The Cronbach's a (alpha) are not standardized and standardized, respectively, 0.868 and 0.871 based on 5 item (variable) values recommended by the statistical literature. The research revealed that students are satisfied with the credibility and trust (44.64\%) and involvement of the company (42.59\%). Also showed they are dissatisfied with the sharing part of the activities (35.71\%), with interpersonal and communication (39.29\%). Also revealed that HR 
contributes to the decision making of your company (72\%), and that decision makers in businesses evaluate the risks that accompany their decisions (86\%).

Key words: Decision making, Personnel management, Strategy.

Introdução

Poucas organizações tem escapado da necessidade de mudança na última década causada pelas novas tecnologias e crises globais. No entanto, o fato de que a mudança tornou-se mais frequente não significa que as mudanças são fáceis. Mudança é, em sua essência, um processo de pessoas, e as pessoas resistem a adoção de novas mentalidades, práticas e comportamentos. Um esforço de transformação de negócios bem sucedido deve capturar os corações e mentes das pessoas que precisam operar de forma diferente tomando decisões para oferecer os resultados planejados.

Nesse cenário de negócios com pressão pela inovação emerge demandas crescentes relacionadas ao desenvolvimento das competências organizacionais e profissionais, levando as empresas a empreenderem mudanças significativas no seu ambiente interno, dentre as quais inclui a gestão de recursos humanos orientada ao desenvolvimento e para a tomada de decisão para a implementação de estratégias organizacionais (CASTELLS, 1999; HAMMER e CHAMPY, 1994; HAMEL e PRAHALAD, 1997; ULRICH, 1998).

Tradicionalmente, as ações de desenvolvimento de pessoas pelo RH é resultante da combinação de práticas e teorias organizacionais que em muitos dos casos, segundo Davel e Vergara (2001), resulta em atividades de tratamento das pessoas como recursos ou fator de produção, estabelecendo uma visão racional, objetiva e normativa da gestão de pessoas.

Alguns fatores são comuns quando as empresas tratam pessoas como recursos de acordo com Ritzer e Trice (1969 apud LEGGE, 1995) em sua pesquisa em empresas americanas: baixa proatividade e dificuldade de antecipação dos problemas das áreas e da organização; passividade e falta de iniciativa; forte ênfase na defesa do status quo, evitando-se, assim, o exercício da liderança; baixa influência na formação do pensamento gerencial; dificuldade para assumir riscos; baixa orientação para os negócios; baixo envolvimento nos aspectos relativos à decisão de negócio; insuficiente prestígio junto aos gerentes.

Além desses fatores, a busca da vantagem competitiva pelas organizações causaram fortes impactos na gestão de pessoas e que colocam as pessoas como a principal fonte de performance de uma organização: interações entre trabalho e tecnologia; alteração nas definições de cargos; introdução de novas categorias de trabalho; forte demanda para aprendizagem contínua; forte impacto da avaliação do consumidor sobre a empresa; mudanças nas funções de liderança e alteração do foco no indivíduo para o trabalho em equipe, (DAVEL e VERGARA, 2001; HANDY, 1991; LEGGE, 1995; ULRICH, 1998), bem como a tomada de decisões (THÉVENER apud DAVEL e VERGARA, 2001).

Na busca a vantagem competitiva, a gestão por competências tornou-se uma tendência da gestão de pessoas. Esta forma de gestão, na prática, desenvolve as seguintes atividades, como foi observado por Fleury e Fleury (2001): (a) captação de pessoas, visando adequar as competências necessárias às estratégias de negócio formuladas, as empresas buscam por pessoas que tenham um nível educacional elevado e, para tal, se valem de programas de trainees, por exemplo, 
considerados fundamentais para atrair novos talentos; (b) desenvolvimento de competências, visto que as empresas contam ainda com a possibilidade de desenvolver as competências essenciais dos indivíduos, através das mais diversas práticas, visando adequá-las às necessidades organizacionais; (c) remuneração por competência, que é uma prática utilizada por empresas preocupadas em resguardar parte do conhecimento tácito de seus colaboradores e mantê-los nas organizações, e vem servindo para que empresas implantem novas formas de remuneração de seus empregados, dentre elas: participação nos resultados, remuneração variável e remuneração baseada nas competências desenvolvidas. Além da remuneração por competência, existe a remuneração por habilidades (CARDOSO (2006).

É importante salientar que a Gestão de Pessoas não ocorre apenas nos Departamentos de Recursos Humanos das organizações. Esta atividade deve ser vista pelos gestores das diversas unidades da companhia como parte do seu trabalho que, se realizado corretamente, permite a empresa atingir seus objetivos estratégicos com maior efetividade. Essas questões são fundamentais para compreender a mudança e a ampliação do foco do RH de uma função administrativa tradicional para uma função estratégica mais abrangente como a tomada de decisão (BECKER, HUSELID e ULRICH, 2001).

O maior desafio da Gestão de Pessoas na tomada de decisões consiste em avaliar as contribuições para o incremento da competitividade e da capacidade da empresa de lidar com desafios vindouros (ULRICH, 1998; BECKER, HUSELID e ULRICH, 2001; LEGGE, 1995). A tomada de decisão é um processo complexo e interdisciplinar do saber e, dentro de empresas e é necessário estudar as alternativas financeiras, de planejamento, de compras, de contabilidade, de informática e etc.

Para tomar decisão o gestor deve analisar os riscos que acompanham a decisão, riscos estes que devem estar o mais próximo possível da realidade. As alternativas para a tomada de decisão estão nas mentes das equipes, e o gestor deve ter a sensibilidade de saber como colocá-las a disposição da resolução da situação problema, a comunicação deve ser aberta e clara, as alternativas para a tomada de decisão não deve vir somente da área problemática, mas também não deve tornar essa exposição das alternativas um brainstorm, pois esse processo pode ser demorado por sair da linha de pensamento do problema, pode-se usar o benchmark como ferramenta caso o problema seja algo em comum entre as empresas, analises numéricas e comparativos com o passado também são boas ferramentas para tomada de decisão.

Segundo Hammonds (2006), por causa da imensa quantidade de regulamentação trabalhista criada pelo governo, o papel do $\mathrm{RH}$ tende a ser absorvido por essa burocracia da regulamentação em uma tendência de proteger os ativos empresariais ao invés de trabalhar para desenvolver a capacidade de tomada de decisões das pessoas. Hammonds (2006), completa: "Os profissionais buscam padronizar e uniformizar uma força de trabalho que é, por natureza, heterogênea e complexa".

Hammonds (2006) enfatiza, ainda, que a "atividade de RH já mostrou ser, na melhor das hipóteses, um mal necessário -e, na pior, uma força burocrática obscura que faz valer regras sem sentido, resiste à criatividade e impede a mudança construtiva". O que tem diferenciado as empresas vencedoras de seus competidores tem sido cada vez mais a qualidade de seus talentos humanos, afirma Hammonds (2006) e, são os gestores de pessoas que têm a função de encontrar essas pessoas e criar oportunidades para que elas se tornem parceiros da empresa e assim tomem decisões estratégicas e tomada de decisões que aumentem o valor da empresa como um todo.

\section{Recursos Humanos}


Por Administração de Recursos Humanos, entende-se uma série de decisões integradas que formam as relações de trabalho; sua qualidade influencia diretamente capacidade da organização e de seus empregados em atingir seus objetivos. A área de RH funciona como um sistema cujas funções e atividades visam atingir objetivos de aumento e equilíbrio sóciotécnico. Todo "gerente" é um Gerente de Recursos Humanos e, portanto, está comprometido com o desafio de analisar, entender, compreender e agir de forma eficiente e eficaz, junto aos Recursos Humanos da sua organização.

Para enfrentar esse enorme desafio de lidar com os recursos humanos, Richard Boyatzis, afirmam Fleury e Fleury (2001), que "reanalisando os dados de estudos realizados sobre as competências gerenciais, identificou um conjunto de características e traços que, em sua opinião, definem um desempenho superior". Para Fleury e Fleury (2001), os trabalhos de (Spencer e Spencer, 1993; McLagan, 1996; Mirabile, 1997) marcaram significativamente a literatura americana a respeito do tema competência.

Nesta perspectiva, o conceito de competência é pensado como conjunto de conhecimentos, habilidades e atitudes (isto é, conjunto de capacidades humanas) que justificam um alto desempenho, acreditando-se que os melhores desempenhos estão fundamentados na inteligência e personalidade das pessoas. Em outras palavras, a competência é percebida como estoque de recursos, que o individuo detém. Embora o foco de analise seja o individuo, a maioria dos autores americanos sinalizam a importância de se alinharem as competências às necessidades estabelecidas pelos cargos, ou posiçôes existentes nas organizações (FLEURY E FLEURY, 2001).

Embora grande parte dos gerentes reconheça as competências empresariais como fonte importante de vantagem competitiva afirmam King, Fowler e Zeithaml (2002), muitas organizações encontram dificuldades em identificá-las e avaliá-las. Para os autores,

A fixação de uma competência compreende a possibilidade de ela ser transferida para outra empresa. A mobilidade de uma competência pode ser medida em um continum que vai de fixo a móvel. A fixaşão é determinada pela localização da competência na organização. As competências podem estar vinculadas ao conhecimento e às habilidades dos funcionários-chave, aos sistemas físicos, tais como bancos de dados, equipamentos e programas de software, aos. sistemas gerenciais, tais como programas de incentivo e estruturas de premiação, e a missão, a cultura ou aos valores que promovem e incentivam certos tipos de conbecimento (KING, FOWLER E ZEITHAML, 2002).

Nesta concepção, para estudar, avaliar, entender e poder administrar os recursos humanos e suas competências, é vital o aprofundamento nas teorias e práticas de comportamento organizacional.

Dopson e Neumann (1998) e Bartlett e Ghoshal (1997), citados por Davel e Melo (2005), indicam a mudança no exercício da autoridade, nos papéis profissionais, nos conhecimentos, no comportamento. Fato que indica a necessidade de o gerente conhecer e influenciar pessoas e compreender a dinâmica interpessoal e as relações entre meio e fim para atingir os objetivos organizacionais. Dessa forma, a área de $\mathrm{RH}$ teve que reorientar não só sua prática, bem como os gerentes quanto aos seus novos papéis, que exigiriam outro aporte de conhecimentos, muitas vezes desconhecidos ou pouco aprofundados pelos profissionais responsáveis por implementálos.

As ações de recursos humanos que, segundo Legge (1995), devem assegurar o comprometimento das pessoas como um recurso valioso para o desempenho organizacional. Legge propõe que a medição dos resultados da função RH deva incidir sobre a análise de processos e práticas direcionadas para o nível individual, de cargos ou atividades específicas, cuja 
melhoria do desempenho se reflita no desempenho da organização. A área de Treinamento e Desenvolvimento é a responsável pelo processo pelo qual a pessoa é prepara para desempenhar tarefas específicas do cargo que deve ocupar de maneira excelente (Chiavenato, 1999).

Ulrich (1998) sugere que os profissionais adotem uma perspectiva mais integradora dos processos de recursos humanos, promovendo a interação da dinâmica do ambiente de negócios com as estratégias de gestão de pessoas a partir dos focos operacional e estratégico, de cuja matriz derivam quatro papéis: parceiro estratégico, cuja função é o ajuste entre o $\mathrm{RH}$, a tomada de decisões e a visão de futuro da empresa; o especialista administrativo, que contribui para a arquitetura dos processos da organização; o defensor dos funcionários, que cria mecanismos de comunicação para as demandas dos empregados; e o agente de mudança, com competência para assegurar a mudança.

A necessidade de que o Departamento de Recursos Humanos possa agir sobre cada gerente, supervisor ou chefe, orientando, influenciando, coordenando e controlando as políticas e práticas de gestão de recursos humanos, exigiu daquele órgão uma evolução técnica sem precedentes nos últimos anos. Principalmente porque foi preciso utilizar várias ciências psicologia, sociologia, política, antropologia, filosofia, comportamento organizacional, etc. - para poder formar o arcabouço teórico e o conjunto de práticas que pudessem suportar o grande desafio que é lidar com pessoas, compatibilizando seus objetivos com os objetivos da organização. E criar condições favoráveis para que elas possam desenvolver-se pessoal e profissionalmente, estabelecendo compromissos mútuos e restituindo a confiança nas relações Capital e Trabalho.

Atualmente, se valoriza o impacto do alinhamento dos sistemas de RH com o esforço de implementação da estratégia organizacional e a tomada de decisões e viabilizar as condições para construir uma estrutura capaz de incorporar as práticas da área de $\mathrm{RH}$ às decisões empresariais no sentido de garantir resultados (ULRICH, 1998). Livian e Burgoyne (1997 apud DAVEL e MELO, 2005:45) apontam as transformações no trabalho dos gerentes como o aumento das responsabilidades e as exigências relacionadas ao desempenho de novos papéis gerenciais, tais como o de coach, a delegação de autonomia, a tomada de decisões entre outros.

Segundo Finkelstein, Whitehead e Campbell (2009) é importante colocar o foco nas pessoas capazes de tomar decisões dentro das organizações. Para ampliar a compreensão sobre o que acontece quando ficam diante de dados desestruturados e incompletos, perspectivas diferentes, pressões de prazo e outras fontes de incerteza.

Assim, a área de Recursos Humanos deverá promover a transição de um modelo gerencial centrado preferencialmente na obtenção de resultados quantitativos para um modelo que, mantendo a lógica do resultado, incorporasse a adequada gestão de pessoas como fator de competitividade empresarial e auxiliar as pessoas desenvolver suas competências em tomada de decisões.

\section{Tomada de Decisão}

As empresas devem ser mais eficientes ao converter escolhas fundamentadas em ações oportunas e devem melhorar o desempenho em três áreas essenciais: (1) melhorar a coleta de dados e informações; (2) estabelecer estrutura para a tomada de decisões; e (3) e praticar a integração das partes organizacionais, principalmente com relação ao compartilhamento das atividades; credibilidade e confiança; comprometimento; relacionamento interpessoal; e comunicação. 
Para mudar, as empresas precisam de uma estrutura que oriente funcionários de todos os níveis à medida que convertem escolhas fundamentadas em ações oportunas, isto é, precisam de uma ação corporativa, o que é fundamental na competição. Tal ação determina uma percepção especifica do conflito e da maneira de decidir.

Henry Mintzberg (2008) afirma que o processo de tomada decisões começa pela definição do problema; depois pelo diagnóstico das causas do problema; em seguida pela formulação das possíveis soluções; por fim a tomada de decisão da melhor alternativa para colocar em prática.

Para Oliveira (2007, p. 142), "decisão é a escolha entre vários caminhos alternativos que levam a determinado resultado". As organizações frequentemente se deparam com problemas sérios de decisão. Enquanto que uma pessoa física pode analisar um problema e escolher alternativas de decisão de maneira informal, nas organizações este processo deve ser metodologicamente estruturado. Sobre o processo de tomada de decisão, Shimizu (2006) argumenta que:

Em uma organização, os problemas são muito mais amplos e complexos, envolvendo riscos e incertezas. Necessitam da opinião e participação de muitas pessoas, em diversos niveis funcionais. O processo de decisão em uma empresa ou organização deve ser estruturado $e$ resolvido de modo formal, detalhado, consistente e transparente (SHIMIZU, 2006, p. 24).

Conforme Oliveira (2007), o processo de tomada de decisão caracteriza-se por cinco momentos. O primeiro momento consiste na identificação da situação que exige uma definição; o segundo consiste em analisar a situação em si; no terceiro momento identificam-se as possibilidades existentes; no quarto momento há a definição de um caminho a seguir; e no quinto momento parte-se para a implementação do curso da ação definida. Oliveira (2007, p. 143) destaca que "a tomada de decisão como ação executiva é a essência da administração. Basicamente, consiste na busca e no caminho a ser perseguido e que seja viável, bem como propicie o melhor resultado final".

Para Simon (1971), o processo decisório se divide em três fases: inteligência, concepção e escolha. Na primeira fase, se processa uma busca ampla por informações que balizem os executivos sobre o estágio atual de desempenho da organização, bem como dos possíveis problemas existentes, em síntese, o sujeito coleta informações para identificar problemas. $\mathrm{Na}$ fase da concepção, projetam-se as possíveis alternativas de soluções disponíveis, isto é, formula-se o problema e se concebe as alternativas. Já na fase da escolha, como o próprio nome já diz, é o momento de optar pelo melhor caminho a seguir, isto é, ocorre a preferência por este ou aquele curso de ação. Para o autor, neste momento, devem-se utilizar ferramentas que possibilitem o cálculo dos custos, consequências e oportunidades de cada uma das alternativas.

As três fases do processo decisório de Simon (1971) são executadas em tempos diferentes: inteligência, concepção e escolha. Tempos depois o autor incluiu uma quarta fase que se relaciona com a implementação da decisão. $\mathrm{Na}$ fase da implantação, introduz-se a alternativa escolhida, convertendo a decisão em ação.

No processo de tomada de decisão, as fases mencionadas não são executadas ao mesmo tempo, apesar da aparente linearidade. Além disso, não necessariamente seguem um caminho padrão, ou seja, do estágio da inteligência para a concepção, escolha e implementação. Em qualquer ponto do processo, talvez tenha que se retornar ao ponto anterior (LAUDON e LAUDON, 1998).

O processo decisório é estudado por Simon (1971) como sinônimo de gerenciamento, tornando clara a proposição sobre a importância das competências e habilidades de tomada de 
decisão de um gestor. As competências e habilidades que envolvem o processo decisório, segundo Simon, podem ser aprendidas e treinadas, daí a importância da evolução do RH.

A tomada de decisão pode ocorrer em diversas condições. Oliveira (2007) salienta que estas condições podem ser: de certeza, de risco ou de incerteza. $\mathrm{O}$ bom administrador se destaca quando a tomada de decisão se processa em um ambiente de certeza. Neste caso, a decisão apresentará menor risco à organização e o curso da sua ação o levará a resultados mais precisos e específicos. O ideal é que todas as decisões no nível operacional sejam tomadas em um ambiente de certeza.

Por se tratar de uma atividade não descartável e de fundamental importância, os estudos do processo decisório refletem a necessidade da busca permanente do aprimoramento da capacidade de decidir. Nesse sentido, decidir pode ser visto como uma escolha entre alternativas que, na maioria das vezes, são afetadas por situações futuras sobre as quais não se tem controle.

\section{Procedimentos Metodológicos}

Para a Metodologia da pesquisa, dividiremos em três categorias de tipologia de pesquisa, quanto aos objetivos, quanto aos procedimentos e quanto à abordagem do problema. A partir da questão problema elaborado: Como o RH contribui para a tomada de decisão estratégica, podemos definir que a tipologia quanto aos objetivos consiste em uma pesquisa descritiva, em que pretendemos descrever quais os impactos dos RH na tomada de decisão. Há a preocupação em analisar situações e comportamentos na população pesquisada. Já quanto aos procedimentos, em que decidimos de qual forma iremos coletar os dados, utilizaremos o levantamento de dados ou SURVEY. Em relação à abordagem do problema, é um estudo do tipo quantitativo, em que usaremos instrumentos estatísticos tanto na coleta de quanto no tratamento de dados.

Conforme McDaniel \& Gates (2003, p. 372), adotou-se o tipo de amostragem nãoprobabilística aleatória, que inclui elementos de uma população selecionados de maneira não aleatória, na base da conveniência, no nosso caso, os alunos existentes em base de dados pessoal, porque são fáceis e baratos de encontrar, porém, com a vantagem de poder ter certeza de obter informações de um corte transversal representativo da população de interesse.

Assim, os dados primários foram obtidos por meio de questionário estruturado, desenvolvido pelo pesquisador eletronicamente no Qualtrics Survey Software disponibilizado no <http://www.Qualtrics.com/> em maio de 2010. Para McDaniel \& Gates (2003, p. 352) com uso de questionários na Internet, os entrevistados completam a pesquisa e os dados são automaticamente coletados e tabulados. As perguntas possuem uma ordem, no entanto, por ser respondida on-line foi permitido aos pesquisados liberdade de avançar e retroceder para opinarem livremente.

Nesse sentido, a população alvo da pesquisa foi constituída por alunos de pós-graduação em administração existentes em base de dados pessoal constituída de 191 alunos. Dos alunos, o total de respondentes foi de 85 , ou seja, a pesquisa de campo apresentou uma amostra de 44,5\% (quarenta e quatro vírgula cinco por cento) da população total, e que obteve o acesso para a efetivação da pesquisa. Desses 85 respondentes, 79 (93\%) responderam todas as questões.

No questionário formulou-se perguntas fechadas, abertas, de múltipla escolha, de avaliação, questões de fato, questões de ação e de intenção, conforme descreve Lima (2004, p. 5071). O questionário para os estudantes apresentou-se com 13 (vinte e quatro) perguntas. $O$ primeiro bloco contemplou os dados sobre o perfil dos respondentes e posteriormente as 
perguntas foram referentes ao tema RH e Tomada de Decisão. Não houve participação nenhuma do pesquisador, ou seja, o questionário ficou a disposição dos respondentes no ar, on-line, e foi preenchido e coletado pelo sistema do Qualtrics Survey Software.

$\mathrm{Na}$ análise de confiabilidade dos dados foi utilizado o aplicativo SPSS, PASWStatistics 18.0, para testar o constructo e medir sua consistência interna. Na figura 1, os coeficientes do Alfa de Cronbach não padronizado e padronizado são, respectivamente, 0,868 e 0,871 com base em 5 item (variáveis). Neste caso, as escalas demonstram a consistência, pois são valores recomendados pela literatura estatística.

\begin{tabular}{|l|c|c|c|c|c|}
\hline & $\begin{array}{c}\text { Credibilidade e } \\
\text { confiança }\end{array}$ & $\begin{array}{c}\text { Compartilhamento } \\
\text { das atividades }\end{array}$ & $\begin{array}{c}\text { Relacionamento } \\
\text { interpessoal }\end{array}$ & Comunicação & Comprometimento \\
\hline $\begin{array}{l}\text { Credibilidade e } \\
\text { confiança }\end{array}$ & 1.000 & .630 & .463 & .622 & .678 \\
$\begin{array}{l}\text { Compartilhamento das } \\
\text { atividades }\end{array}$ & .630 & 1.000 & .498 & .535 & .644 \\
$\begin{array}{l}\text { Relacionamento } \\
\text { interpessoal }\end{array}$ & .463 & .498 & 1.000 & .498 & .464 \\
$\begin{array}{l}\text { Comunicação } \\
\text { Comprometimento }\end{array}$ & .622 & .535 & .498 & 1.000 & .716 \\
\hline
\end{tabular}

Figura 1: Matriz de Correlação

Reliability Statistics

\begin{tabular}{|c|c|r|}
\hline $\begin{array}{c}\text { Cronbach's } \\
\text { Alpha }\end{array}$ & $\begin{array}{c}\text { Cronbach's } \\
\text { Alpha Based } \\
\text { on } \\
\text { Standardized } \\
\text { Items }\end{array}$ & N of Items \\
\hline .868 & .871 & 5 \\
\hline
\end{tabular}

Figura 2: Output do Alfa de Cronbach do PASW 18

Por fim, completando a análise de confiabilidade dos resultados, os testes de F ANOVA (figura 3) e Hotelling's T (figura 4) que apontam que medias variáveis são idênticas e, pelo teste Tukey, não existe interação entre as variáveis analisadas.

ANOVA with Tukey's Test for Nonadditivity

\begin{tabular}{|c|c|c|c|c|c|c|c|}
\hline & & & $\begin{array}{l}\text { Sum of } \\
\text { Squares }\end{array}$ & df & Mean Square & $\mathrm{F}$ & Sig \\
\hline \multicolumn{3}{|l|}{ Between People } & 237.274 & 53 & 4.477 & & \\
\hline \multirow[t]{5}{*}{ Within People } & \multicolumn{2}{|c|}{ Between Items } & 8.059 & 4 & 2.015 & 3.402 & .010 \\
\hline & Residual & Nonadditivity & $.022^{\mathrm{a}}$ & 1 & .022 & .037 & .847 \\
\hline & & Balance & 125.519 & 211 & .595 & & \\
\hline & & Total & 125.541 & 212 & .592 & & \\
\hline & Total & & 133.600 & 216 & .619 & & \\
\hline Total & & & 370.874 & 269 & 1.379 & & \\
\hline
\end{tabular}

Grand Mean $=4.45$

a. Tukey's estimate of power to which observations must be raised to achieve additivity $=.751$.

Figura 3: Teste F ANOVA 
Hotelling's T-Squared Test

\begin{tabular}{|c|c|r|r|c|}
\hline $\begin{array}{c}\text { Hotelling's T- } \\
\text { Squared }\end{array}$ & $\mathrm{F}$ & $\mathrm{df1}$ & $\mathrm{df2}$ & $\mathrm{Sig}$ \\
\hline 19.120 & 4.510 & 4 & 50 & .003 \\
\hline
\end{tabular}

Figura 4: Teste Hotelling's T

\section{Resultados e Análise da Pesquisa}

O perfil dos alunos apresentou as seguintes características: 61\% são mulheres entre 18 a 25 anos (63\%), solteira (71\%), com superior incompleto (75\%), trabalhadores $(79 \%)$, em empresas acima de 500 pessoas (48\%).

Perguntado se a o RH contribui para a tomada de decisão de sua empresa, $72 \%$ responderam que sim, como mostra a tabela 1 . Isso demonstra que as grandes empresas ajudam seus colaboradores na tomada de decisão. Para mudar, as empresas precisam de uma estrutura que oriente funcionários de todos os níveis a medida que convertem escolhas fundamentadas em ações oportunas e regras comuns para a tomada de decisão (FULLER, 1999).

Tabela 1: Contribuição do RH para a tomada de decisão.

\begin{tabular}{|c|l|l|c|c|}
\hline$\#$ & Resposta & & Pergunta & $\%$ \\
1 & Sim & Não & 42 & $72 \%$ \\
2 & Total & & 16 & $28 \%$ \\
\hline & Tol & 58 & $100 \%$ \\
\hline
\end{tabular}

Fonte: dados da pesquisa

Sobre os responsáveis pela área de $\mathrm{RH}$ da sua empresa, 49\% estão mais preocupados com o desenvolvimento da empresa como um todo, $32 \%$ preocupados com a rotina, $11 \%$ com as relações interpessoais e $9 \%$ com a busca pela padronização da força de trabalho conforme demonstrado na tabela 2. Essa preocupação é percebida na discussão sobre as pressões do cenário econômico pela inovação emerge demandas crescentes relativas ao incremento das competências organizacionais e profissionais levando as empresas a empreenderem mudanças expressivas no seu ambiente interno, nas quais se inclui a gestão de recursos humanos que deve ser inserido no desenvolvimento e na tomada de decisão para a implementação de estratégias organizacionais (CASTELLS, 1999; HAMMER e CHAMPY, 1994; HAMEL e PRAHALAD, 1997; ULRICH, 1998).

Tabela 2: Preocupação com o desenvolvimento da empresa.

\begin{tabular}{|c|c|c|c|}
\hline \# & Resposta & Pergunta & $\%$ \\
\hline 1 & As relações interpessoais & 6 & $11 \%$ \\
\hline 2 & A rotina burocrática do departamento pessoal & 18 & $32 \%$ \\
\hline 3 & A busca pela padronização da força de trabalho & 5 & $9 \%$ \\
\hline 4 & $\begin{array}{l}\text { O desenvolvimento da empresa para que haja } \\
\text { um aumento de seu valor como um todo }\end{array}$ & 28 & $49 \%$ \\
\hline
\end{tabular}


Fonte: dados da pesquisa

Perguntados se os tomadores de decisão de sua empresa avaliam os riscos que acompanham suas decisões, $86 \%$ acreditam que sim, demonstrado na tabela 3 . O que confirma a discussão de Ritzer e Trice (1969 apud LEGGE, 1995) que afirmam que alguns fatores são comuns no tratamento de pessoas como recursos como a dificuldade para assumir riscos.

Tabela 3: Avaliação dos riscos que acompanham as tomadas de decisões.

\begin{tabular}{|c|l|l|c|c|}
\hline$\#$ & Resposta & & Pergunta & $\%$ \\
1 & Sim & & 48 & $86 \%$ \\
2 & Não & & 8 & $14 \%$ \\
\hline & Total & & 56 & $100 \%$ \\
\hline
\end{tabular}

Fonte: dados da pesquisa

$86 \%$ consideram as tomadas de decisão da sua empresa como eficazes e apenas $14 \%$ consideram não eficazes, como mostra a tabela 4. Pois para tomar uma boa decisão o gestor deve calcular e administrar os riscos que acompanham a decisão, riscos estes que devem estar o mais próximo possível da realidade e com maior eficácia. Podemos observar, ainda, que como o processo decisório é uma sequência de etapas que vai desde a identificação da situação até a escolha e solução de problemas. De acordo com Maximiano (2000), os problemas e as situações variam muito em termos de natureza, urgência, risco, impacto sobre a organização e outros fatores.

Tabela 4: Eficácia na tomada de decisão.

\begin{tabular}{|c|l|l|c|c|}
\hline$\#$ & Resposta & & Pergunta & $\%$ \\
1 & Sim & & 48 & $86 \%$ \\
2 & Não & & 8 & $14 \%$ \\
\hline & Total & & 56 & $100 \%$ \\
\hline
\end{tabular}

Fonte: dados da pesquisa

Ao solicitar a avaliação sobre a credibilidade e confiança das empresas, 44,64\% dos entrevistados estão satisfeitos, com relação ao compartilhamento das atividades, $35,71 \%$ estão parcialmente satisfeitos, sobre o relacionamento interpessoal, 39,29\% estão parcialmente satisfeitos, em termos de comunicação, 39,29\% dos respondentes estão parcialmente satisfeitos, e por ultimo, $42,59 \%$ estão satisfeitos com o comprometimento da empresa. Vide tabela 5.

Tabela 5: Avaliação dos entrevistados perante suas respectivas empresas

\begin{tabular}{|c|l|c|c|c|c|c|c|}
$\#$ & $\begin{array}{c}\text { Muito } \\
\text { insatisfeito }\end{array}$ & Insatisfeito & $\begin{array}{c}\text { Parcialmente } \\
\text { insatisfeito }\end{array}$ & $\begin{array}{c}\text { Parcialmente } \\
\text { satisfeito }\end{array}$ & Satisfeito & $\begin{array}{c}\text { Muito } \\
\text { satisfeito }\end{array}$ \\
\hline 1 & $\begin{array}{l}\text { Credibilidade e } \\
\text { confiança }\end{array}$ & $1.79 \%$ & $5.36 \%$ & $5.36 \%$ & $17.86 \%$ & $\mathbf{4 4 . 6 4 \%}$ & $25.00 \%$ \\
\hline 2 & $\begin{array}{l}\text { Compartilhamento } \\
\text { das atividades }\end{array}$ & $0.00 \%$ & $8.93 \%$ & $10.71 \%$ & $\mathbf{3 5 . 7 1 \%}$ & $30.36 \%$ & $14.29 \%$ \\
\hline
\end{tabular}




\begin{tabular}{|c|l|c|c|c|c|c|c|}
\hline 3 & $\begin{array}{l}\text { Relacionamento } \\
\text { interpessoal }\end{array}$ & $5.36 \%$ & $1.79 \%$ & $5.36 \%$ & $\mathbf{3 9 . 2 9 \%}$ & $23.21 \%$ & $25.00 \%$ \\
\hline 4 & Comunicação & $0.00 \%$ & $12.50 \%$ & $7.14 \%$ & $\mathbf{3 9 . 2 9} \%$ & $25.00 \%$ & $16.07 \%$ \\
\hline 5 & $\begin{array}{l}\text { Comprometiment } \\
\text { o }\end{array}$ & $0.00 \%$ & $7.41 \%$ & $7.41 \%$ & $25.93 \%$ & $\mathbf{4 2 . 5 9 \%}$ & $16.67 \%$ \\
\hline
\end{tabular}

Fontes: dados da pesquisa

Ao solicitar a avaliação sobre o processo de tomada de decisão nas empresas, 45,9\% dos entrevistados estão parcialmente satisfeitos, com relação a formulação do problema, 44,7\% estão parcialmente insatisfeitos, sobre o diagnóstico das causas, 35,3\% estão parcialmente insatisfeitos, em termos de possíveis soluções, $27,1 \%$ dos respondentes estão parcialmente insatisfeitos com a tomada de decisão, e por ultimo, 27,1\% estão satisfeitos com a aplicação da decisão na empresa, conforme tabela 6 .

Tabela 6: Avaliação dos entrevistados perante suas respectivas empresas

\begin{tabular}{|c|c|c|c|c|c|c|c|}
\hline \# & Barra & $\begin{array}{c}\text { Muito } \\
\text { insatisfeito }\end{array}$ & Insatisfeito & $\begin{array}{l}\text { Parcialmente } \\
\text { insatisfeito }\end{array}$ & $\begin{array}{c}\text { Parcialmente } \\
\text { satisfeito }\end{array}$ & Satisfeito & $\begin{array}{c}\text { Muito } \\
\text { satisfeito }\end{array}$ \\
\hline 1 & $\begin{array}{l}\text { Formulação do } \\
\text { problema }\end{array}$ & $2,4 \%$ & $2,4 \%$ & $4,7 \%$ & $45,9 \%$ & 7,1 & $3,5 \%$ \\
\hline 2 & $\begin{array}{l}\text { Diagnóstico das } \\
\text { causas }\end{array}$ & $0,0 \%$ & $5,9 \%$ & $44,7 \%$ & $9,4 \%$ & $4,7 \%$ & $1,2 \%$ \\
\hline 3 & $\begin{array}{l}\text { Formulação das } \\
\text { possíveis soluções }\end{array}$ & $4,7 \%$ & $5,9 \%$ & $35,3 \%$ & $12,9 \%$ & $3,5 \%$ & $3,5 \%$ \\
\hline 4 & $\begin{array}{l}\text { Tomada de } \\
\text { decisão }\end{array}$ & $4,7 \%$ & $9,4 \%$ & $27,1 \%$ & $14,1 \%$ & $7,1 \%$ & $3,5 \%$ \\
\hline 5 & $\begin{array}{l}\text { Aplicação da } \\
\text { decisão }\end{array}$ & $1,2 \%$ & $4,7 \%$ & $4,7 \%$ & $18,8 \%$ & $27,1 \%$ & $7,1 \%$ \\
\hline
\end{tabular}

Fontes: dados da pesquisa

O processo de tomada de decisão nas organizações vem sofrendo alterações, sobretudo com o desenvolvimento das tecnologias de informação. Herbert A. Simon, afirma que tomar decisões é o trabalho mais importante de qualquer executivo, assim como o mais arriscado (SIMON, 1971). Ele acrescenta que o trabalho do executivo consiste não apenas em tomar decisões próprias, $35,71 \%$ responderam que estão parcialmente satisfeito em relação ao compartilhamento das decisões, mas também providenciar que toda a organização que dirige, ou parte dela, tome-as também de maneira efetiva, como podemos observar que $42,59 \%$ dos respondentes estão satisfeitos com o comprometimento.

Para Simon (1971), o processo decisório é sinônimo de gerenciamento, tornando clara a proposição sobre a importância das habilidades de tomada de decisão de um gestor. Uma decisão pode ser também entendida como uma oportunidade, que envolve interesse, desafio e perspectiva de recompensa (Maximiano, 2000). Importante, ainda, lembrar Davenport e Prusak (1998) que o uso da informação permite aos gestores tomarem melhores decisões sobre processos e produtos, aprendendo, se relacionado/ comunicando dentro da empresa com seus pares, bem como fora da empresa com os clientes e com a concorrência e monitorando os resultados de suas ações. Podemos observar que nas grandes empresas, tabela 5, esses fatores são positivos.

Assim, para dar subsídio a formulação dos processos e práticas de RH para auxiliar a tomada de decisões, a produtividade, a inovação e o controle gerencial nesta área. O que 
possibilita aos gestores analisar e monitorar as tendências e suas respectivas implicações para a estratégia empresarial, evitando-se a tomada de decisão baseada nas impressões ou apenas na experiência empírica e não sistematizada.

\section{Considerações finais}

A combinação dos objetivos individuais com os objetivos organizacionais, ambientados na realidade social que envolve a empresa, bem como a intensidade e a qualidade das transações que se realizam entre os diversos atores, sejam eles acionistas, empregados, fornecedores, clientes ou outros interessados, definem o sucesso ou insucesso da organização ao longo do tempo. As políticas de Recursos Humanos que contemplam a perenidade desses objetivos, apoiadas em tomadas de decisões que viabilizam a sua realização, colocam a organização em vantagem competitiva, pois estará preparada para maximizar o aproveitamento das oportunidades de minimizar o efeito das ameaças, mesmo que sejam crises conjunturais provocadas por fatores que fogem ao seu controle. Daí a necessidade de se promover a estreita integração entre RH e Tomada de Decisão, assegurando-se a identidade de objetivos entre os diversos colaboradores através de um processo planejado e executado com o compromisso de todos os segmentos e estratos do corpo de colaboradores e interessados no sucesso da organização.

O sucesso dos recursos humanos e de um processo de tomada de decisão eficaz que a empresa adota para satisfazer às demandas e anseios dos setores responsáveis pelos seus produtos e serviços, é determinado por todos os colaboradores existentes, principalmente pelos gestores, que independentemente da área em que atua são gestores de pessoas.

A tomada de decisão nas organizações vai exigir cada vez mais trabalhos em equipe e maior participação das pessoas. O trabalho em equipe coloca em evidência os procedimentos de diálogo baseados na ideia de que, em uma organização, a comunicação deve ser estimulada visando ao estabelecimento de um pensamento comum (ANGELONI, 1992). O estabelecimento de um pensamento comum consiste em considerar o ponto de vista de cada um, para que as decisões tomadas nas organizações tenham um nível de qualidade superior. O processo decisório passa então do nível individual para o nível de equipe.

Considerando que nenhuma pessoa detém todas as informações e conhecimentos organizacionais e que nem sempre estas informações e conhecimentos estão explicitados e disponíveis, fazendo com que cada um detenha apenas uma parte deles, a tomada de decisão em equipe é uma forma a ser utilizada para superar as barreiras das informações e conhecimentos parciais.

A tomada de decisão que envolve um maior número de pessoas tende a resultados mais qualificados, aumentando o conhecimento da situação de decisão, amenizando, pela agregação de informações e conhecimentos, as distorções da visão individualizada.

Pessoas com pontos de vistas e experiências diferentes decodificam a situação de decisão também de maneira diferente. Ouvir e tentar compreender essas visões leva ao aprimoramento das decisões. As decisões tomadas em equipes tendem a ser mais sólidas que as tomadas individualmente, apesar de, normalmente, demandarem mais tempo.

A presente pesquisa apresenta algumas limitações, a saber: (a) trata-se de uma investigação empírica, conduzida com estudantes de pós-graduação de São Paulo, pesquisadas em maio de 2010 , portanto, não se refere esta pesquisa a qualquer outro período de tempo, outra região geográfica ou objeto; (b) os pesquisados forma convidados a responder questionários específicos, presumindo-se que as respostas obtidas foram dadas efetivamente pelos 
respondentes aquém os questionários foram endereçados eletronicamente e expressam a opinião dos respondentes. Dessa forma, apenas este conjunto de respostas foi levado em conta; (c) os dados coletados foram analisados por técnicas estatísticas acima descritas, consideradas adequadas à tipologia ordinal dos dados, pelo que os resultados das análises não levam em conta outras possíveis observações decorrentes do uso de outros instrumentos analíticos.

A pesquisa também é limitada pelos seguintes aspectos: (a) trata-se de uma pesquisa nãoprobabilística e, por este fato, não é possível extrapolar os resultados para outros alunos professores; (b) os resultados obtidos referem-se apenas ao conjunto de respondentes pesquisados considerando-se que as respostas aos questionários exprimem, de fato, o pensamento dos respondentes.

\section{Referências Bibliográficas}

BAUMANN, R. et al. O Brasil e a economia global. Rio de Janeiro: Campus, 1996.

BECKER, B. E.; HUSELID, M. A.; ULRICH, D. Gestão Estratégica de pessoas com scorecard: interligando pessoas, estratégia e performance. Rio de Janeiro: Campus, 2001.

CASTELLS, M. A sociedade em rede. São Paulo: Paz e Terra, 1999.

CARDOSO, L. R. Avaliando Sistemas de Remuneração Baseados em Habilidades e Competências: a visão dos profissionais de gestão de pessoas. Revista Brasileira de Gestão de Negócios, v. 8, n. 21, p. 13-23, 2006.

CHIAVENATO, Idalberto. Desempenho humano nas empresas: como desenhar cargos e avaliar o desempenho. São Paulo: Atlas, 2001, p.105-155.

CHIAVENATO, Idalberto. Recursos Humanos. Avaliação do Desempenho. São Paulo: Atlas, 1998.

COUTINHO, L.; FERRAZ, J. C. Estudo da competitividade da indústria brasileira. Campinas: Papirus, 1995.

DAVEL, E.; MELO, M. C. O. Singularidades e transformações no trabalho dos gerentes. In: (Orgs.). Gerência em ação: singularidades e dilemas do trabalho gerencial. Rio de Janeiro: Editora FGV, 2005.

DAVEL, E.; MELO, M. C. O.; VERGARA, S. C. Gestão com pessoas e subjetividade. São Paulo: Atlas, 2001.

DAVENPORT, T. H.; PRUSAK, L. Ecologia da informação: Por Que só a Tecnologia não Basta para o Sucesso na Era da Informação. São Paulo: Futura, 1998.

DEMO, P. Complexidade e aprendizagem: a dinâmica não-linear do conhecimento. São Paulo: Atlas, 2002.

DRUCKER, Peter Ferdinand. Administração da instituição de serviço público. Fator humano e desempenho: O melhor de Peter F. Drucker sobre a administração. São Paulo: Pioneira, 2002. p.162-175.

FINKELSTEIN, S.; WHITEHEAD, J. \& CAMPBELL, A. Ferramenta previne erros nas decisões. HSM Management, 75, Julho-agosto, 2009.

FLEURY, Maria Tereza Leme; FLEURY, Afonso. Construindo o conceito de competência. Rev. adm. contemp., Curitiba, v. 5, n. spe, 2001. Disponível em <http://dx.doi.org/10.1590/S141565552001000500010>. Acesso em 17 jan. 2012. 
FULLER, Mark B. Lições da Guerra. HSM Management, 12, Janeiro-fevereiro, 1999.

HAMEL, G.; PRAHALAD, C. K. Competindo pelo futuro. Rio de Janeiro: Campus, 1997.

HAMMER, M.; CHAMPY, J. Reengenharia: revolucionando a empresa em função dos clientes, da concorrência e das grandes mudanças da gerência. Rio de Janeiro: Campus, 1994.

HAMMONDS, Keith. Por que Odiamos o RH. HSM Management, 55, março-abril, 2006.

HANDY, C. A era da irracionalidade. Lisboa: Edições CETOP, 1991.

LAUDON, K. C.; LAUDON, J. P. Management Information Systems : New Approaches to Organization and Technology. Nova Jersey: Prentice Hall, 1998.

LEGGE, Karen. Human resource management: rethorics and realities. Houndmills, Basingstoke, Hampshire, England: MacMillan Business, 1995.

MAXIMIANO, Antonio Amaru. Introdução a Administração. São Paulo: Atlas, 2000.

MINTZBERG, Henry. Primeiro pense, primeiro veja, primeiro faça. HSM Management, 69, Julho-Agosto, 2008.

OLIVEIRA, D. P. R. de. Sistemas de informações gerenciais, São Paulo: Atlas, 2007.

SHIMIZU, Tamio. Decisão nas organizações. São Paulo: Atlas, 2006.

SIMON, H. A. The New Science of Management Decision. New York: Harper and Brothers Publishers, 1960.

SIMON, H. A. Comportamento administrativo: estudo dos processos decisórios nas organizações administrativas. Rio de Janeiro: FGV, 1971.

ULRICH, D. Os campeões de recursos humanos: inovando para obter os melhores resultados. São Paulo: Futura, 1998.

WILCOX KING, Adelaide; W. FOWLER, Sally; P. ZEITHAML, Carl. Competências organizacionais e vantagem competitiva: o desafio da gerência intermediária. Revista administração de empresas, São Paulo, v. 42, n. 1, mar. 2002. Disponível em <http://dx.doi.org/10.1590/S0034-75902002000100005>. Acesso em 17 jan. 2012. 